Andrzej Bonasewicz

\title{
POLOGNE. DONNÉES RÉCENTES SUR LES MOUVEMENTS MIGRATOIRES INTERNATIONAUX
}

Après la chute du communisme et le changement du régime en 19891990, la Pologne, traditionnellement pays d'émigration, est devenue aussi un pays d' immigration. Les années quatre-vingt, pendant lesquelles env. 1 million de personnes quittent la Pologne, contrastent avec les années quatrevingt-dix, caractérisées par une intensité du mouvement frontalier sans précédent. Ainsi, 61 millions de personnes traversent la frontiere polonaise en 1992, 82 millions en 1995, 89 millions en 1999.

Les migrations définitives augmentent aussi, dont surtout les immigrations. Les cartes de séjour définitif, les cartes de travail, les droits d'asile, les retours des Polonais vivant à l'extérieur sont de plus en plus nombreux. 100 à 150000 étrangers travaillent en Pologne illégalement.

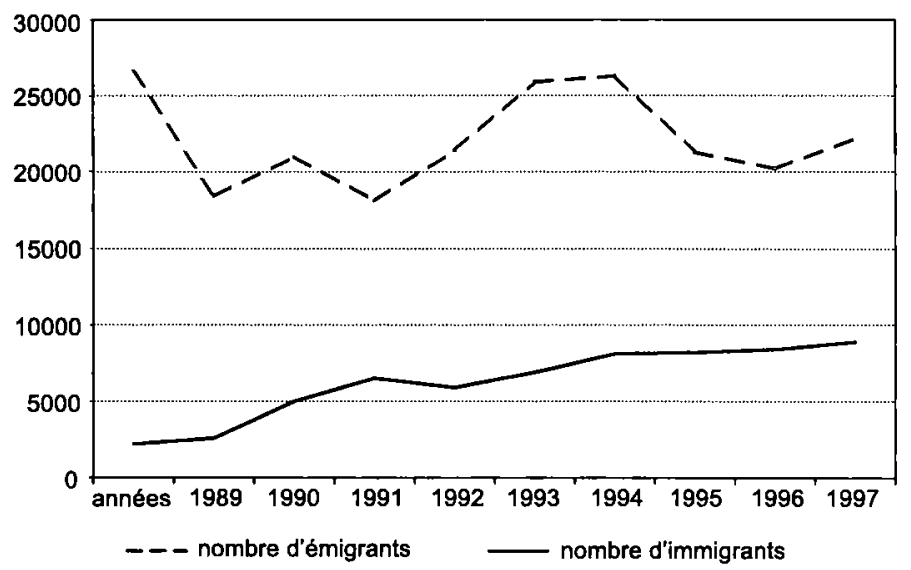

L'émigration dépasse bien sûr l'immigration, mais, en dix ans, l'écart a sensiblement diminué. Le nombre de départs - 20 à 25000 personnes par an - ne change guère. Les destinations ne changent pas non plus: 70 à $73 \%$ d'émigrants se dirigèrent vers l'Allemagne (toujours les Polonais et les Al- 
lemands qui rejoignent leurs familles en République Fédérale), 10\% aux États-Unis et 6-7\% au Canada (surtout les personnes ayant leurs familles en Amérique; ce groupe a légèrement augmenté avec la libéralisation des droits d'entrée pour les ressortissants des pays d'Europe Centrale et Orientale), $2 \%$ vers l'Australie (aussi pour rejoindre leur proches), 1 à $2 \%$ vers la France (où les départs ont diminué suite aux restrictions administratives de plus en plus rigoureuses). Le reste des émigrants - 7 à $8 \%$ - se dirigèrent vers d'autres pays de l'Union Européenne et vers la République d'Afrique du Sud.

La prédominance des contacts de la Pologne avec l'Allemagne est donc aussi sensible dans le domaine des mouvements migratoires. Cette prédominance se reflète également dans les statistiques concernant l'origine des émigrants: près de $60 \%$ étaient originaires de la Silésie, surtout de la HauteSilésie (la voïvodie de Katowice totalisant $32 \%$ de départs) et de la région de Gdańsk - donc des territoires appartenant jadis à l'Allemagne.

En ce qui concerne les caractéristiques des émigrants, il est à noter que, en dix ans, la proportion des femmes a diminué (de 55 à $50 \%$ ) et la proportion des jeunes entre 18 et 24 ans a augmenté (de 17 à $23 \%$ ). On cherche donc l'emploi et le nombre de Polonais travaillant à l'étranger est estimé à 200-300 000, dont 180000 en Allemagne.

L'immigration en Pologne est un phénomène nouveau. Elle augmente d'année en année et aurait été beaucoup plus sensible si les difficultés administratives n'étaient pas aussi restrictives.

C'est toujours l'Allemagne qui fournit le plus grand nombre d'immigrants: $17 \%$ en 1989, $26 \%$ en 1997. Il s'agit des Polonais qui retournent dans leur patrie après le changement du régime, des Allemands qui ont conservé leurs familles en Pologne, des hommes d'affaires. Viennent ensuite les ressortissants de l'ex-URSS (12\% en 1989, 23\% en 1997): Polonais anciennement déportés, Ukrainiens, Russes, Biélorusses, Arméniens et Kazakhs mariés à des personnes de nationalité polonaise. Les retours des États-Unis constituèrent $19 \%$ des arrivées en 1989 et $14 \%$ en 1998, ceux du Canada respectivement 4 et $5 \%$, d'Australie -3 et $2 \%$, de la Grande-Bretagne -6 et $3 \%$, de France - 4\%, d'Autriche - 1 et $2 \%$.

Les réfugiés constituent un groupe à part. Là aussi les demandes de droit d'asile ont considérablement augmenté dans les années quatre-vingt-dix. Au début, c'étaient surtout les Bosniaques, les Yougoslaves et les Éthiopiens, ensuite les Arméniens, enfin les ressortissants de Sri Lanka, d'Afghanistan et d'Irak. Les Somaliens étaient aussi toujours présents. Les autorisations pour bénéficier du droit d'asile étaient délivrées au compte-goutte. Les refus (ils concernaient surtout les Arméniens, les Hindous, les Pakistanais, les ressortissants du Bangladesh) devraient être normalement accom-pagnés de mesures d'expulsion - mais nombreux sont ceux qui ne quittent jamais la Pologne. Elle est habituellement considérée comme pays de transition, en destination de l'Union Européenne.

La Pologne devient donc, après le changement de régime, un pays de plus en plus intéressant pour les migrants. Il s'agit aussi bien de l'immigration en 
provenance des pays développés (les retours des personnes d'origine polonaise - mais également les arrivées des hommmes d'affaires) que du TiersMonde. Bien que cette immigration, pour des raisons économiques, soit administrativement freinée, elle ne cessera certainement pas d'augmenter. Il faut s'attendre surtout à des retours d'anciens déportés et de leurs descendants, vivant toujours au Kazakhstan; au moins 20000 d'entre eux souhaiteraient revenir, alors qu'en dix ans 2000 seulement se sont établis en Pologne. 
